\title{
Optimization of operation scheme for express freight railway
}

\author{
Hong Xiao ${ }^{1}$, Shu Huang ${ }^{1}$, Bo Hang ${ }^{2, *}$, Xiao-kun Wang ${ }^{3}$ \\ ${ }^{1}$ School of Economics and Management, Chongqing Jiaotong University \\ Chongqing 400074, China \\ ${ }^{2}$ Computer School, Hubei University of Arts and Science \\ Xiangyang 441053, China \\ ${ }^{3}$ School of Economics and Management, Dalian Jiaotong University \\ Dalian 116028, China \\ "Corresponding Author: oceanisland214@163.com
}

\begin{abstract}
With the high-speed development of industrialization process and the Internet e-commerce in China, the number of the fast cargoes is increasing. The transportation demands of customer should be provided in a convenient and efficient way. However, compared to road and aviation, railway express freight network is lagging in China, the market share is relatively low, and the service is still in a low level. The operation scheme of railway express freight train can improve the railway efficiency. This paper studies the railway express freight train schemes on several related questions. They are as follows: (1) We analyze the factors of operating express freight train. (2) Based on the assumption of the shortest path for the flow of traffic, the operation scheme of express freight railways is optimized by establishing a multi-target model with making the largest railway revenue and the largest satisfaction of cargo owner. (3) The multi-target model is proposed to be converted into a single-target model. It is the case of carrying out the operation scheme in the four logistics node cities of the southwest China. The following conclusions are taken: (1) The choice method of the flow path is generally analyzed by heuristic method, which is more accurate. (2) We establish a multi-objective optimization model on the base of getting the maximum of transport revenue and satisfying the cargo owner's demand.
\end{abstract}

Keywords: Operation scheme; optimization model; railway express freight.

\section{Introduction}

With the high-speed development of the industrialization process and the Internet e-commerce in China, the number of fast cargoes is increasing. These fast cargoes are parcels, and the products consist of machinery, electronics, light textiles, and food industry. These cargoes have special requirements on delivery time and push the transportation operations to a high level (Wang \& He, 2017).

Express railway freight transportation has high requirements on the delivery time. The main service object is the high-value-added cargoes. According to the specific transportation organization method, an express railway freight transportation system needs to be rapid, accurate, safe and convenient. The most basic feature of express railway freight transportation is timeliness. The cargoes must be transported to the destination according to the delivery time that is promised to the owner, and the cargoes integrity and traceability in the process must be ensured. These cargoes have the characteristics of short storage time, small batches, multiple batches, etc., and they must be transported with convenience and safety. The express railway freight network has provided more favorable guarantees for these cargoes. The target of China's Medium- and Long-Term Railway Network Plan (2016) is 2035, and the scale of the railway network will reach 150,000 kilometers, of which 30,000 kilometers will be high-speed railways, covering more than $80 \%$ of large cities (Figure 1). 


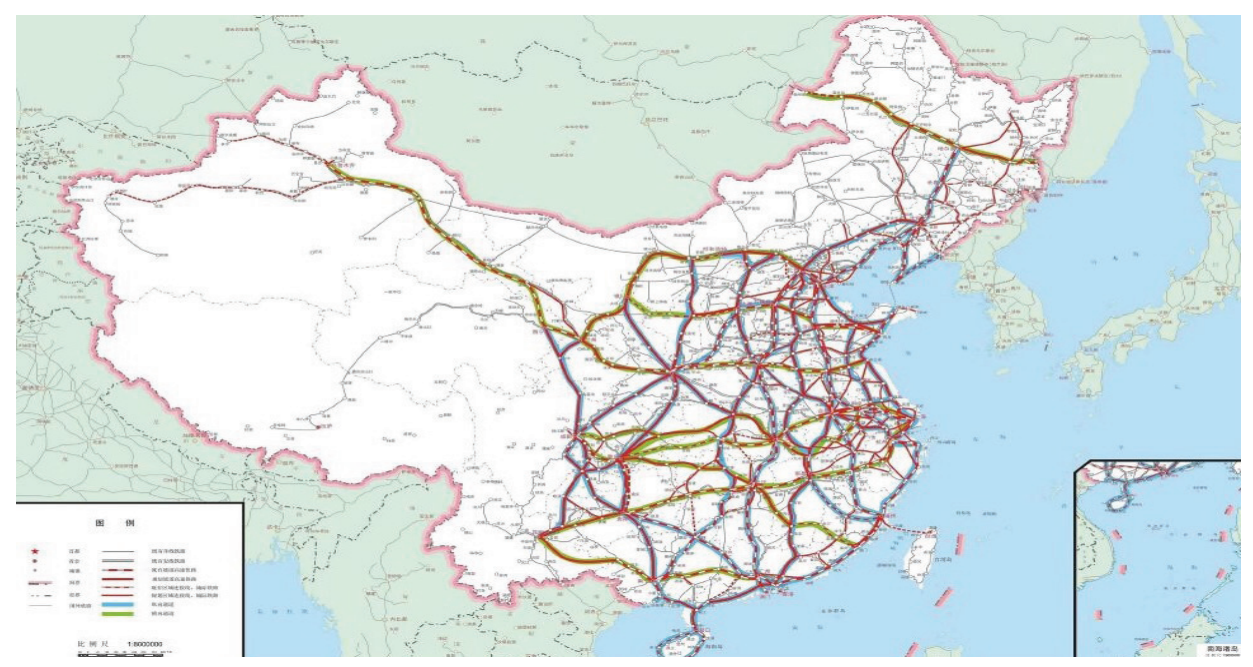

Fig. 1. China's medium- and long-term express railway network plan.

Planning and operating railway transportation systems are extremely hard due to the combinatorial complexity of the underlying discrete optimization problems, the technical intricacies, and the immense sizes of the problem instances. Precisely because of that, mathematical models and optimization techniques can result in huge gains for both railway customers and operators, e.g., in terms of cost reductions or service quality improvements (Borndörfer et al., 2017). Many researchers devoted to the discrete and continuous network design problem (NDP) for road transportation. Some of them aimed at determining the optimal capacity expansions of the links by using continuous decision variables (Wang et al., 2015). Lin et al. (2002) addressed the decision for the railway network design problem (RNDP) to determine where a new railway line should be built, or where an existing railway line should be strengthened based on the project investment and cost of routing cars. Yan et al. (2007) discussed the impact of limited investment on the railway project's choice and developed a model of RNDP in several plan stages. In recent years, air pollution has become a severe environmental problem. Although the railway transport is considered to be the most environmentally friendly type of transport, The European Union (EU) has set a target objective of modal shift from road freight transport towards other more sustainable transport modes of $30 \%$ by 2030 and of at least $50 \%$ by 2050 , for shipments over $300 \mathrm{~km}$ (Dolinayova et al., 2016). Many countries are seeking effective methods to reduce carbon emissions. Among the sources of air pollution, the transportation industry is a large one. Lin et al. (2017) analyzed the carbon emissions of railway and highway transport and estimated the environmental benefit of building a railway. They also recommended a bi-level programming model for the railway network.

Railway system is an interesting topic. Planning and operating railway transportation systems are extremely hard due to the combinatorial complexity of the underlying discrete optimization problems, the technical intricacies, and the immense sizes of the problem instances. In the last years, a large and growing group of researchers in the operations research (OR) community have devoted their attention to this domain developing mathematical models and optimization approaches in the railway planning process. Borndörfer et al. (2017) and Cacchiani \& Toth (2012) surveyed the optimization literature and focused on particular aspects addressed by the mathematical models. They also demonstrated on concrete applications how mathematical optimization can support railway planning and operations. Zhao et al. (2017) thought railway systems contained various endogenous and exogenous disturbances that might lead the train operation to deviate from the basic schedule. Due to increasing traffic demand and limited infrastructure expansion, the schedules of current railway networks were highly susceptible to even small operational disturbances.

Railway systems must increase their performance and economic competitiveness to remain an effective and efficient transport mode. Efficiency goals are one of the main drivers for the future evolution of planning and operations of transport systems. For each freight train, 
the associated train operator specifies a preferred ideal timetable, which can be modified by the infrastructure manager in order to respect safety operational constraints. In particular, this modification may correspond to routing the train along a path, which is different with respect to the one in the ideal timetable. The fact that only actual timetables with positive profit are of interest limits the possible arrival and departure times of each train at each station, leading to implicit time window constraints. The express freight train operation scheme is the core of the train operation plan, and the plan is optimized to meet the specific objectives, which can improve the operational efficiency of the transportation department and meet the needs of cargo owners. Therefore, how to choose a better one from the alternatives is particularly important (Hou et al., 2019).

This paper establishes a multi-objective model for the optimization of the operation scheme of express freight trains. For the multi-objective planning model, the general solution is to change multi-objective into a single objective to obtain a satisfactory solution. There are two common ways to turn multi-objective optimization issues into single-target combination optimization problems; these are as follows: (1) One is to change the two-objective problem into a weighted sum problem, then a new target function can be obtained by multiplying each target function by a weight factor added. (2) The other is to change one of the objective functions into a constraint, to transform the multiobjective model into a single objective model.

In this paper, we change one of the objective functions into a constraint, to transform the multi-objective model into a single objective model. Taking the four logistics node cities in the southwest of China as an example, the case study is carried out on the optimization method of the operation scheme.

\section{Factors influencing the selection of wagon path}

The wagon path is the route where the vehicle passes from the starting station to the terminal station. It is an important basis for the preparation of the driving plan. Therefore, the following factors should be considered in the optimization of the wagon path.

(1) The mileage of a railway line can be determined according to The Freight Tariff Odometer.

(2) The transport time required for the train from the departure station to the destination station is " $\mathrm{T}$ ". The calculation formula is

$T=\sum \frac{L_{m}}{V_{m}}+\sum t_{1}+\sum t_{2}$

" $L_{m}$ " is the length of each section through which the train passes; " $V_{m}$ " represents the running speed of each section of the train; " $t_{1}, t_{2}$ " indicate the transit time of the train station passing through the technical station and the transit time of the transfer.

(3) The passing capacity of each section through which the train runs, and the adaptation operation capacity of each technical station can be determined by statistical data.

(4) The total cost of the train from the originating station to the final station can be calculated.

\section{Establishment of an optimization model for train operation plan}

We study the optimization of the operation scheme of railway express freight train under the condition of known train and vehicle and line equipment. It neither involves technical equipment nor does it involve daily scheduling problems. When establishing the optimization model of the development plan, the benefits of the transportation department and the transportation demand of the shippers need to be considered. At the same time, it is necessary to determine the operation section, frequency, and number of groups of express freight trains under the condition of the road network. In order to simplify the problem, the following assumptions are made:

(1) The train running path is determined by the shortest path.

(2) The capacity of receiving and dispatching vehicles at different stations can meet the requirements of fast freight traffic.

(3) Only considering the cargo flow, the goods and transportation conditions are not discussed.

(4) Determine the cargo flow in the attracting area of each node

The bases of knowing the shortest path between all $\mathrm{O}$ and $\mathrm{D}$ and the original shipments between $\mathrm{O}$ and $\mathrm{D}$ are allocated to the respective sections of the corresponding path, which serves as the basis for the trains running between the nodes. The shortest path between nodes " $\mathrm{i}$ " and node " $\mathrm{j}$ " in the network is expressed as " $r_{i j}$ ", the 
section of any two adjacent nodes is called " $e_{m}$ ", and the distance between the two adjacent sections is expressed as " $k_{m}$ ", then the relationship between section $\mathrm{m}$ and the shortest path " $r_{i j}$ "can be expressed as

$x_{i j m}= \begin{cases}1 & m \in r_{i j} \\ 0 & m \notin r_{i j}\end{cases}$

The number of changing jobs between nodes " $\mathrm{i}$ " and node "j" can be expressed by variable " $\delta_{\text {od }-i j}$ ".

$\delta_{o d-i j}= \begin{cases}n & \text { If the train is switched on the } \mathrm{N} \text { station on the way } \\ 0 & \text { If the train does not carry out operation on the way }\end{cases}$

$q_{\text {od }}$ The volume of an actual cargo transport between arbitrary $\mathrm{O}$ and $\mathrm{D}$.

$c_{1}$ - The cost per unit of train operation and locomotive traction cost per $\mathrm{km}$. The unit is yuan / vehicle kilometer.

$c_{2}$ - The cost of changing trains at the station the unit is yuan/times.

I - The operating revenue of each vehicle running by the express freight train is RMB / vehicle $\mathrm{km}$.

$q_{o d-i j}-$ The flow of freight between any $\mathrm{O}$ and $\mathrm{D}$ between trains running between nodes I and J.

$N_{o d}$ The demand for cargo transport between $\mathrm{O}$ and D.

$f_{i j}$ The opening frequency of the train between nodes "i" and "j".

$L_{\min } \longrightarrow$ The minimum number of marshalling cars of the train.

$L_{\max }-$ The maximum number of marshalling cars of the train.

$n_{i j m}$ - The total freight volume of trains running through section $\mathrm{m}$ between nodes "i" and " $\mathrm{j}$ ".

There are two main objectives of the railway express freight train scheme. The first is to meet the shipper's transportation needs as much as possible. The second is to improve the operating efficiency of transportation enterprises. In this way, it can not only ensure the operating efficiency of transportation enterprises, but also ensure the transportation efficiency.

(1) Meet freight demand maximization

The more freight the railway transports, the greater the degree to which the shipper's freight demand is satisfied.
Its expression is

$\max z_{1}=\sum_{o d}\left(q_{o d} / N_{o d}\right)$

(2) Transport enterprises maximize operating benefits

The operating benefits of transportation enterprises are divided into two parts: train operating incomes and train operating costs. The operating incomes are expressed as "I" that is related to the vehicle kilometer. The operating costs are mainly considered in two parts: the cost of using lines and locomotives $\left(c_{1}\right)$ and the cost of changing trains at stations $\left(c_{2}\right)$. The expression of the target function is

$\max z_{2}=\sum_{o d} \sum_{i j} \sum_{m}\left(I-c_{1}\right) q_{o d-i j} k_{m}-\sum_{o d} \sum_{i j} m_{2} q_{o d-i j} \delta_{o d-i j}$

The constraints are as follows:

(1) Traffic and transport demand constraints

Sometimes, the total amount of goods transported on each route cannot fully meet the freight demand. The expression is

$q_{o d} \leq N_{o d}$

According to the conservation of traffic flow, the actual volume of goods transported between order (0) and destination (D) is equal to the total volume of goods transported on the passing segment "m". All freight volume between " $\mathrm{i}$ " and " $\mathrm{j}$ " shall be the sum of freight volume between "O" and " $\mathrm{D}$ ". The expression is

$q_{o d}=q_{\text {odm }}$

$q_{o d m}=\sum_{i j} q_{o d-i j} x_{i j m}$

\section{(2) Train operation conditions}

Railway trains need to be organized at a specified number of vehicles. The traffic flow of all trains passing through section " $\mathrm{m}$ " shall be within a certain number of marshals. The expression is:

$$
\begin{aligned}
& f_{i j} L_{\min } \leq n_{i j m} \leq f_{i j} L_{\max } \\
& n_{i j m}=\sum_{o d} q_{o d-i j} x_{i j m}
\end{aligned}
$$

(3) Nonnegative constraints

$$
\begin{aligned}
& f_{i j} \geq 0 \\
& q_{o d-i j} \geq 0
\end{aligned} \text { (They are integers) }
$$


Based on the shortest route of the traffic flow, consider the satisfaction degree of the freight owner's transportation demand and the operation benefit of the transportation enterprise.

Then, we can build a multi-objective optimization model for the running scheme of express freight trains.

$$
\begin{aligned}
& \max z_{1}=\sum_{o d}\left(q_{o d} / N_{o d}\right) \\
& \max z_{2}=\sum_{o d} \sum_{i j} \sum_{m}\left(I-c_{1}\right) q_{o d-i j} k_{m}-\sum_{o d} \sum_{i j} m_{2} q_{o d-i j} \delta_{o d-i j}
\end{aligned}
$$

s.t.

$q_{o d} \leq N_{o d}$

$q_{o d}=q_{o d m}$

$q_{o d m}=\sum_{i j} q_{o d-i j} x_{i j m}$

$f_{i j} L_{\min } \leq n_{i j m} \leq f_{i j} L_{\max }$

$n_{i j m}=\sum_{o d} q_{o d-i j} x_{i j m}$

$f_{i j} \geq 0$ (It's an integer)

$q_{o d-i j} \geq 0$ (It's an integer)

By optimizing the value of $f_{i j}, q_{o d-i j}, \delta_{o d-i j}$ in this model, the optimal objective function can be achieved, and the train running scheme can be determined.

For the multi-objective planning model, the general solution is to change the multi-objective into a single objective to obtain a satisfactory solution. There are two common ways to turn multi-objective optimization issues into single-target combination optimization problems; these are as follows: (1) One is to change the twoobjective problem into a weighted sum problem, then a new target function can be obtained by multiplying each target function by a weight factor added. (2) The other is to change one of the objective functions into a constraint, to transform the multi-objective model into a single objective model. In this paper, we change one of the target functions into a constraint, so we convert multi-objective into a single objective problem.

The single objective model is as follows:

$$
\max z_{2}=\sum_{o d} \sum_{i j} \sum_{m}\left(I-c_{1}\right) q_{o d-i j} k_{m}-\sum_{o d} \sum_{i j} c_{2} q_{o d-i j} \delta_{o d-i j}
$$

s.t.

$$
\begin{aligned}
& (1-\varepsilon) N_{o d}-\sum_{i j} q_{o d-i j} x_{i j m} \leq 0 \\
& \varepsilon \in[0,1] \\
& f_{i j} L_{\min }-\sum_{o d} q_{o d-i j} x_{i j m} \leq 0 \\
& \sum_{o d} q_{o d-i j} x_{i j m}-f_{i j} L_{\max } \leq 0 \\
& f_{i j} \geq 0 \text { (It's an integer) } \\
& q_{o d-i j} \geq 0 \text { (It's an integer) } \\
& 0 \leq \delta_{o d-i j} \leq n \text { (It's an integer) }
\end{aligned}
$$

Genetic algorithm is one of the best ways for traffic problems. Genetic algorithm is a random optimization algorithm based on Darwin's genetic selection and the biological evolution principle of the fittest. The genetic algorithm first formed a possible set of solutions into an initial population. Individuals in a population are chromosomes with their characteristics, which are composed of multiple genes that are internally represented by a combination of certain genes. In each evolution process, the individual is selected by the size of the individual value, and then after selection, cross-over, and variation operation, a new generation, which is adapted to the environment, is more adapted to the environment than the previous generation, and the optimal solution will eventually be produced after this process. Then, the optimal solution is produced, decoding the genetic language into a practical problem.

As an intelligent optimization method of efficient, parallel and global search, the genetic algorithm should be widely used to solve optimization problems such as the path optimization in a system. In this paper, we take the genetic algorithm to solve the optimization problems of traffic path.

Four logistics node cities (Chengdu, Chongqing, Guiyang, and Nanning) were selected to design the operation scheme.

(1) Transportation network. The distance between node cities is shown in Table 1. 
Table 1. Distance between node cities (Unit: km).

\begin{tabular}{lllll}
\hline & Chengdu & Chongqing & Guiyang & Nanning \\
\hline Chengdu & 0 & 330 & 803 & 1678 \\
Chongqing & 330 & 0 & 473 & 1348 \\
Guiyang & 803 & 473 & 0 & 875 \\
Nanning & 1678 & 1348 & 875 & 0 \\
\hline
\end{tabular}

(2) Data between O and D. The traffic volume of four logistics node cities is shown in Table 2.

After consulting relevant data and data of Chengdu railway bureau, the average load of an express freight train is set as 60 tons, calculated by 30 days per month.
Then, the O-D cargo volume in a month is converted into O-D traffic volume in the day, and the daily traffic volume between these cities in the logistics nodes can be obtained, as shown in Table 3.

Table 2. The average monthly express freight volume of logistics node cities in 2013 (Unit: kg).

\begin{tabular}{lllll}
\hline \multicolumn{1}{c}{ O } & Chengdu & Chongqing & Guiyang & Nanning \\
\hline Chengdu & - & 36000 & 77398 & 16199 \\
Chongqing & 32389 & - & 89979 & 61189 \\
Guiyang & 52191 & 16194 & - & 37795 \\
Nanning & 26990 & 12587 & 35982 & - \\
\hline
\end{tabular}

Table 3. The average daily traffic volume of high value-added goods between node cities (Unit: train/day).

\begin{tabular}{lllll}
\hline O & Chengdu & Chongqing & Guiyang & Nanning \\
\hline Chengdu & - & 20 & 43 & 9 \\
Chongqing & 18 & - & 50 & 34 \\
Guiyang & 29 & 9 & - & 21 \\
Nanning & 15 & 7 & 20 & - \\
\hline
\end{tabular}

According to the model, solve the model with MATLAB7.11. The values of each variable are as follows: I=10 (Yuan/vehicle kilometers), c1=2.4 (Yuan/vehicle kilometers), $\mathrm{c} 2=100$ (Yuan/vehicle). $q_{\min }=20, q_{\min }=40$.

After solving, z=1712200, "qod -ij” and "fij” are shown in Table 4 and Table 5.

Based on the results of Table 4 and Table 5, the operation scheme of intercity trains at four logistics nodes (Chengdu, Chongqing, Guiyang, and Nanning) can be obtained, shown in Table 6.

From the results of the operation scheme, it can be seen that the average daily traffic of trains running in 12 sections is 271 trains in four logistics node cities. The demand flow is 275 trains, indicating that freight demand is up to $98.5 \%$.

On the other hand, the train organization forms between different regions are diversified. For example, the trains to Guiyang are mostly direct trains; the trains to Chengdu are mostly combination trains. The running frequency of trains is once a day, which is consistent with the distribution of high value-added goods between nodal cities and regional channels. Therefore, the operation scheme of the model is reasonable. 
Table 4. Express freight traffic.

\begin{tabular}{|c|c|c|c|c|}
\hline \multicolumn{2}{|c|}{ od } & \multicolumn{2}{|c|}{ ij } & \multirow{2}{*}{$\begin{array}{c}\text { qod-ij } \\
20\end{array}$} \\
\hline Chengdu & Chongqing & Chengdu & Nanning & \\
\hline Chengdu & Guiyang & Chengdu & Nanning & 11 \\
\hline Chengdu & Nanning & Chengdu & Nanning & 9 \\
\hline Chongqing & Guiyang & Chongqing & Guiyang & 40 \\
\hline Chongqing & Guiyang & Chongqing & Nanning & 10 \\
\hline Chongqing & Nanning & Chengdu & Nanning & 20 \\
\hline Chongqing & Nanning & Chongqing & Nanning & 14 \\
\hline Guiyang & Nanning & Chengdu & Nanning & 11 \\
\hline Chengdu & Guiyang & Chengdu & Guiyang & 32 \\
\hline Guiyang & Nanning & Chongqing & Nanning & 10 \\
\hline Guiyang & Chongqing & Guiyang & Chengdu & 5 \\
\hline Guiyang & Chengdu & Guiyang & Chengdu & 15 \\
\hline Chongqing & Chengdu & Guiyang & Chengdu & 5 \\
\hline Nanning & Guiyang & Nanning & Chengdu & 18 \\
\hline Nanning & Chongqing & Nanning & Chengdu & 7 \\
\hline Guiyang & Chongqing & Nanning & Chengdu & 4 \\
\hline Nanning & Chengdu & Nanning & Chengdu & 15 \\
\hline Guiyang & Chengdu & Nanning & Chengdu & 14 \\
\hline Chongqing & Chengdu & Nanning & Chengdu & 11 \\
\hline
\end{tabular}

Table 5. Express freight train operating range and frequency.

\begin{tabular}{ccc}
\hline Origin & Destination & Operation frequency \\
\hline Chengdu & Nanning & 1 \\
Chengdu & Guiyang & 1 \\
Chongqing & Guiyang & 1 \\
Chongqing & Nanning & 1 \\
Nanning & Chengdu & 1 \\
Guiyang & Chengdu & 1 \\
\hline
\end{tabular}

\section{Conclusions}

With the implementation of China's railway freight reform, railway express freight has received extensive attention. Based on the development demand of railway express freight transportation, this paper mainly studies the operation scheme optimization of an express freight train by using the theory and method of operational research. After taking into account the benefits of transportation department and the satisfaction degree of freight owner transportation demand, this paper establishes the multi-objective model of operation scheme and proposes the solution method. The train operation form between different regions presents a variety of characteristics. In this case, most of the cars, which go to Guiyang, are direct, and most of the cars, which go to Chengdu, are a combination of trains. But the frequency of operation is the same, once a day, which is basically consistent with the traffic volume in the node city and also consistent with the distribution of high value-added goods in these regional areas. 
Table 6. Railway express freight scheme.

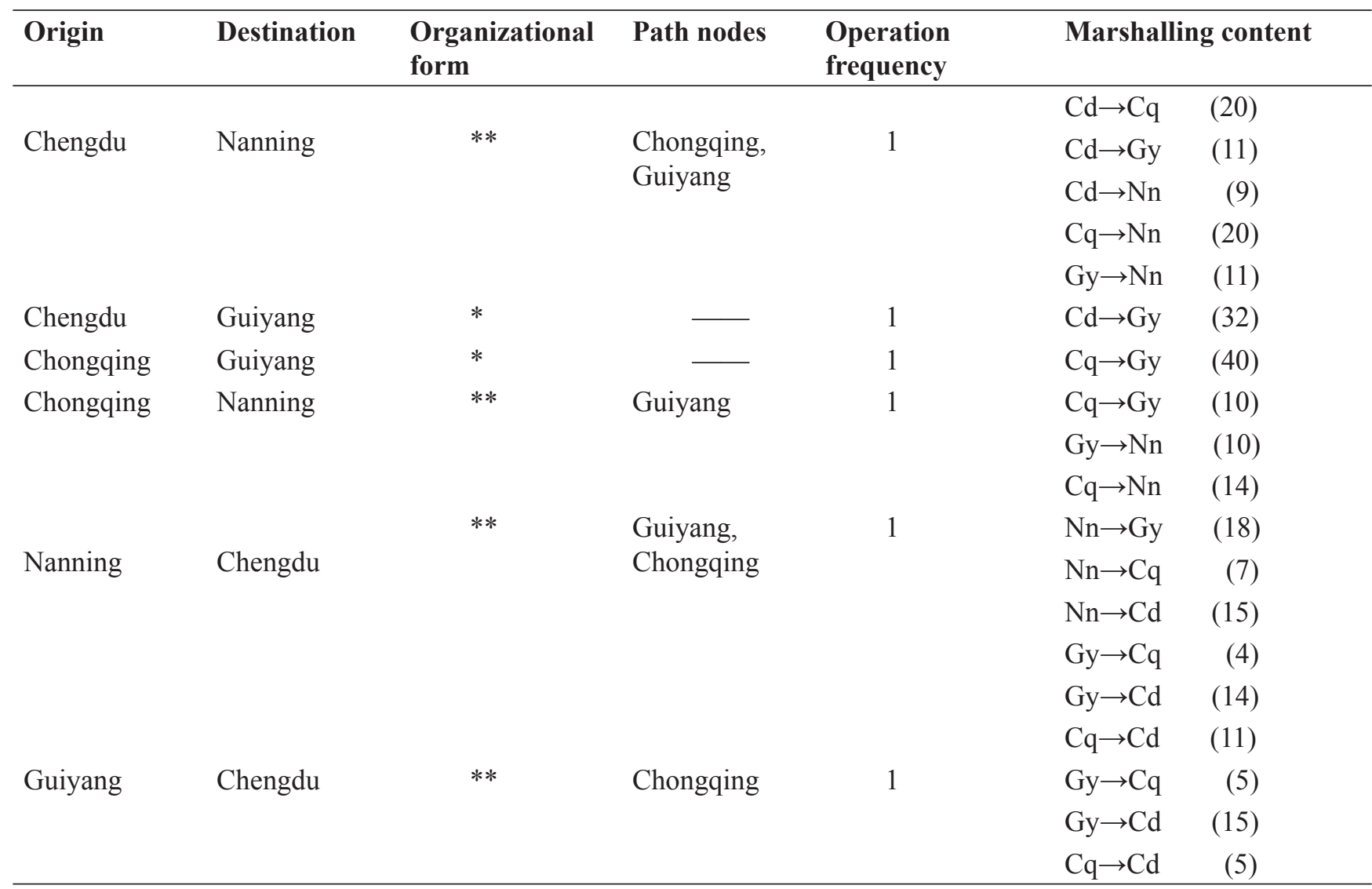

* means direct train, ${ }^{* *}$ means change the trailer in the middle.

Railway network is a complex network, and it is a huge project to study the optimization of the operation scheme of railway express freight trains in the railway network. Therefore, this study has complexity and fuzziness, and the actual situation will be more complex and uncertain.

1. This paper summarizes the existing express freight products in China, including five scheduled lines, railway parcel lines, railway express lines, high-speed rail express lines, and express lines.

2. This paper compares and analyzes the selection methods of traffic path, such as the shortest path method, mathematical model method, and heuristic method. Then, the road network environment applicable to various methods is obtained.

\section{ACKNOWLEDGEMENTS}

The authors wish to thank Science and Technology Development Program of Central Guide to Local Government of China, for its support of the project (No. 2019ZYYD043), and the authors also wish to thank International Science \& Technology Cooperation
Program of Hubei Province, for its support of the project (No. 2019AHB059).

\section{References}

Borndörfer, R., Klug, T., Lamorgese, L.,Mannino, C., Reuther, M. \& Schlechte, T. (2017). Recent success stories on integrated optimization of railway systems. Transpor. Transportation Research Part C: Emerging Technologies, 74:196-211

Cacchiani, V. \& Toth, P. (2012). Nominal and robust train timetabling problems. European Journal of Operational Research, 219(3):727-737.

Dolinayova, A., Kanis, J. \& Loch, M. (2016). Social and economic efficiency of operation dependent and independent traction in rail freight. Procedia Engineering, 134:187-195

Hou Y.W., Zhu C.F., Yuan J.S. \& Wang J. (2019). Preferred methods of railway express freight train operation plan. Journal of Railway Science and Engineering, 16(5):1329-1336. 
Lin, B., Liu, C., Wang, H. \& Lin, R. (2017). Modeling the railway network design problem: a novel approach to considering carbon emissions reduction. Transportation Research Part D: Transport and Environment, 56: 95109.

Lin, B.L., Xu, Z.Y., Huang, M. \& Guo, P.W. (2002). An optimization model to railroad network designing. Journal of the China Railway Society. 24(2):1-6.

Wang, D.Z.W., Liu, H. \& Szeto, W.Y. (2015). A novel discrete network design problem formulation and its global optimization solution algorithm. Transportation Research Part E: Logistics and Transportation Review, 79:213-230.

Wang, B.H. \& He S.W. (2017). Resource Planning Optimization Model and Algorithm for Multi-modal, Express Shipment Network, Journal of the China Railway Society, 39(2):10-16.

Yan, H., Lin, B. \& Liang, D. (2007). An optimization model of railroad network design and investment including multiple projects in several five-year plans. Journal of China Railway Society, 29(3):19-24.

Zhao W.T., Ullrich, M., Cui Y.\& Liang, J. (2017). Operational risk analysis of block sections in the railway network. Journal of Rail Transport Planning \& Management, 7:245e262.

Submitted : 05/05/2019

Revised : $21 / 01 / 2020$

Accepted : 23/02/2020

DOI $\quad: 10.48129 /$ kjs.v48i1.7800 